\title{
Effect of referral for dental service on dental- service utilization by primary school children
aged 8 to 11 years in Enugu, Nigeria
}

\author{
Nneka Kate Onyejaka' ${ }^{1}$, Morenike Oluwatoyin Folayan ${ }^{2}$, Nkiruka Folaranmi ${ }^{1}$ \\ ${ }^{1}$ University of Nigeria, Department of Child Dental Health, Enugu, Enugu state, Nigeria
}

${ }^{2}$ Obafemi Awolowo University, Faculty of Dentistry, Oral Habit Study Group, lle-Ife, Osun state, Nigeria

\begin{abstract}
Aim: To determine how one dental education session and referral of study participants aged 8-11 years would affect utilization of oral-health care services. Methods: This descriptive prospective study recruited 1,406 pupils aged 8-11 years from randomly selected primary schools in Enugu metropolis. All pupils received one oral-health education and referral letters for treatment. Data were collected on the pupils' socio-demographic profile, family structure, and history of oral-health care utilization in the 12 months preceding the study and within 12 months of receipt of referral letter. The effect of these factors as predictors of past and recent dental service utilization was determined using logistic regression. Results: Only $4.3 \%$ of the study participants had ever used oral-health services in the 12 months prior to the study. Within 12 months of issuing the referral letters, $9.0 \%$ of pupils used the oral-health services. Children from middle (AOR: $0.46 ; \mathrm{Cl}: 0.29-0.73 ; p=0.001$ ) and low socioeconomic strata (AOR: $0.21 ; \mathrm{Cl}: 0.11-0.39 ; p<0.001$ ) and those living with relatives/ guardians (AOR: $0.08, \mathrm{Cl}: 0.01-0.56 ; \mathrm{p}=0.01$ ) were still less likely to have utilized oral-health services. Conclusions: Referral of children for oral-health care increased the number of children who utilized oral health care services.
\end{abstract}

Keywords: Physician Self-Referral. Oral Health. Utilization.

\section{Introduction}

Regular preventive dental attendance is a contributor to the oral-health status of people of all ages ${ }^{1}$. Many factors affect utilization of oral-health care services: socioeconomic status ${ }^{2,3}$, attitude towards dental care ${ }^{4}$, family structure ${ }^{5}$, proximity to oral-healthcare centers ${ }^{6}$, being an immigrant ${ }^{7}$, and ability to take time out for dental visits $^{8}$. These factors interplay, resulting in a synergistic effect that may worsen the effect of independent factors on the risk of poor utilization of oral-healthcare services. However, when primary care services are delivered for children using the one-stop-shop model, it increases dental service utilization for both preventive and curative care 9 .

Underutilization of oral health care services can lead to poor oral health and impact

Received for publication: July 19, 2016 Accepted: November 16, 2016

Correspondence to: Onyejaka Nneka Kate Department of Child Dental Health, University of Nigeria, Enugu, Nigeria. Phone: +2348037449279

E-mail: nnekaonyejaka@yahoo.com negatively on the oral health quality of life ${ }^{10}$. Untreated dental diseases like dental caries may lead to dental pain and impact on the child's daily activities like playing, sleeping, eating and school activities ${ }^{11}$. Reports from sub-Saharan Africa show very low utilization of oral healthcare services and visits are mostly after symptoms have developed $^{12}$. Similarly, studies in the Western region of Nigeria show low utilization of oral-health services by children, with visits often prompted by oral symptoms like pain ${ }^{13,14}$. Efforts at promoting utilization of dental service by children in Nigeria 
have resulted in significant, but still low, dental service visits. Moreover, these visits continued to be for curative rather than preventive purposes ${ }^{15}$. The need to promote children's access to oral-health services in Nigeria has been the major focus of many public oral health interventions ${ }^{15,16}$.

There is dearth of information on any project that breaks barrier of utilization of oral health care services in Southeastern Nigeria. This study is an effort towards identifying mechanisms that can help improve dental service utilization by schoolchildren in Enugu Metropolis, Nigeria. Specifically, the study sought to identify if one dental educational session and referral of study participants 8-11 years old for both preventive and curative treatment. It assessed if it would increase the number of pupils who utilized oral health care services over a 12 months period when compared to the number of pupils that used oral health care services in prior years.

\section{Material and methods}

Study design: This was an observational prospective study. For this were enrolled pupils aged 8-11 years, schooling in the three LGAs in the Enugu metropolis of Enugu State. Enugu State is one of the 36 states in Nigeria. Its population is mostly the Igbo ethnic group of Nigeria. Most of the Enugu State inhabitants have monogamous families ${ }^{17}$ with an average of 4.8 children per family ${ }^{17}$. There is no public data on the oral health service utilization by the study population.

To calculate the sample size using the formula of Araoye ${ }^{18}$ based on a $15 \%$ prevalence of oral-health centre utilization by children in Lagos $^{12}$, a $5 \%$ margin of error and a confidence level of $95 \%$, we estimated that, after referrals, approximately 200 pupils would eventually visit the dental clinics. To get a referred population of 200 pupils, the total sample size targ would be $1,333.3$, rounded up to 1,400 pupils. A total of 30 primary schools to visit in order to recruit 1,400 pupils aged 8 to 11 years from a total school population of 41,853 pupils ${ }^{19}$ of the same age group was 30 .

A multistage stratified sampling technique was used to enroll study participants. The first stage involved selection of a proportional representation of the schools per LGA. The second stage involved the random selection of classes with large populations of children aged 8-11 years. The class registration list, which showed the age of the students, was used to determine the classes with the highest number of pupils aged 8 to 11 years. The third stage involved the selection of 47 study participants from two classes in each school.

\section{Study tool}

A three-part form was developed for the study. The first part contained questions that elicited information on age at last birthday, gender, residential address and the socioeconomic status. The socioeconomic status of each child's family was derived by the multiple indices obtained from a scoring index, which combined with the mother's level of education and the father's occupation; social stratification based on this combination increases its validity 20 . The distance of the student's residence to the closest dental service point was determined by use of a handheld Global Positioning System (GPS) Garmin map 76csx, which determined distances in degrees, minutes and seconds (DMS). This device used point data and coordinate details of the residence and the closest dental clinic based on data collected in the field. The coordinated data were converted by use of Tatuk Geographic Information System (GIS) calculator from DMS to decimal degrees to enable the details to be inserted into the Arc GIS software. The data were then exported from Arc GIS to Quantum GIS for determining the distance matrix (point data analysis).

The second section contained questions that elicited information on the family structure. It included information on the type of family (monogamous, polygamous), number of siblings, birth position and family structure (living with parents, single parent, stepmother or other relatives).

The third section elicited information on past utilization of oral-healthcare service, including the past dental visits (yes, no), date of last visit, reasons for last visit (pain, routine), type of treatment given (scaling and polishing, oral hygiene education, restorations, extractions), and address of the visited dental clinic.

\section{Study procedure}

Dentists working at all the registered dental clinics in Enugu metropolis were contacted and the aims and objectives of the study were explained to them. Dentists were encouraged to ask parents of children 8-11 years old if they were attending the dental clinic after the referrals ask for their referral letters and collect them. Details of the dental treatment given for each child were required to be filled in specific sections of the referral letter. Where referral letters could not be produced by the parent of the child, the details of the child and the dental treatment offered were to be entered into a form provided for the dentists.

Three dentists were enrolled as field workers and trained on the data collection procedure and details of the study collection tool. Discussions and clarifications about content of the questionnaire were also made during the review of the outcomes of the field testing.

Pupils recruited for the study provided responses to the questions. All questionnaires were administered by the trained field workers. Information about the type of family (monogamous, polygamous), number of siblings, birth position and family structure (living with parents, single parent, step mother or other relatives) of the child was also sought from the teachers of the study participants when they could not readily provide these information. Missing data was obtained through telephone interviews of the parents using phone numbers provided by the study participants.

Oral-health education was provided to all pupils in the class, irrespective of whether they were enrolled for the study or not, after filling the study form. All study participants were given referral letters to visit any registered oral-health center of their choice within the Enugu metropolis. The list of registered dental clinics and their addresses was attached to the referral letter addressed to their parents/guardians. Children were encouraged to take the referral letters with the demand to leave them at the clinics they visited. 
The study's principal investigator visited the registered dental clinics within Enugu metropolis every month for 12 months to retrieve the referral letters and collect data on the types of dental treatment each child received.

Twelve months after the school visit, the principal investigator re-visited the schools and obtained information about the purpose of the dental visit(s) from pupils who visited dental clinics. Clarifying information was obtained from the parents of the study participants when they could not provide the required information. The information from the child and the parent was needed to corroborate the information coming from the dental clinics and to identify other patients who may have made visits to dental clinics and whose details were not captured through the visits of the principal investigator to the dental clinics to retrieve referral letters. Oral-health education was also provided to all pupils in their classrooms at this second visit, using the same oral-health education curriculum.

\section{Data analysis}

Statistical Package of Social Science (SPSS) version 15 was used to analyze the collected data. Descriptive analysis was conducted by use of a wide variety of measures of location (mean and mode) and dispersion (deviation). These data are represented as tables. Bivariate analysis was conducted to test the association between the child's socioeconomic status, type of family, family structure, birth position, family size, distance from child's residence to the closest dental clinic, and history of oral-health service utilization before and after study intervention. A model was developed that included those factors that were significantly associated with health-service utilization and logistic regression conducted to identify the factors that played specific roles in utilization for the study population. The level of statistical significance was set at $\mathrm{p}<0.05$.

\section{Ethical consideration}

Ethical approval for the study was obtained from the University of Nigeria Health Research Ethics Committee (IRB 00002323). Permission was also obtained from school authorities in the Enugu metropolis prior to the commencement of the study. Written informed consent was obtained from the mothers of children who participated in the study and assent was also obtained from the children.

\section{Results}

A total of 1,408 pupils were eligible to participate in the study. Two children refused to continue with study participation following recruitment, leaving the total number of participants at 1,406 . Their mean age $\pm(\mathrm{SD})$ was $9.32 \pm(1.08)$ years; $9.42 \pm$ (1.09) years for the boys and $9.23 \pm(1.07)$ years for the girls.

Table 1 shows that the study participants included $52.2 \%$ females, $37.1 \%$ of children from the higher socioeconomic stratum, $95.4 \%$ of children from monogamous families, and $84.4 \%$ of children living with both parents. Also, $40.5 \%$ of study participants had 3-4 siblings.
Table 1 - General characteristics of the study participants $(\mathrm{n}=1,406)$.

\begin{tabular}{|c|c|}
\hline Variables & Frequency $\mathrm{n}(\%)$ \\
\hline \multicolumn{2}{|l|}{ Age (years) } \\
\hline 8 & $418(29.7)$ \\
\hline 9 & $372(26.5)$ \\
\hline 10 & $363(25.8)$ \\
\hline 11 & $253(18.0)$ \\
\hline \multicolumn{2}{|l|}{ Gender } \\
\hline Male & $672(47.8)$ \\
\hline Female & $734(52.2)$ \\
\hline \multicolumn{2}{|l|}{ Socioeconomic status } \\
\hline High & $521(37.1)$ \\
\hline Middle & $439(31.2)$ \\
\hline Low & $446(31.7)$ \\
\hline \multicolumn{2}{|l|}{ Type of family } \\
\hline Monogamy & $1341(95.4)$ \\
\hline Polygamy & $65(4.6)$ \\
\hline \multicolumn{2}{|l|}{ Family structure } \\
\hline Both parents & $1186(84.4)$ \\
\hline One parent & $46(3.2)$ \\
\hline Relative/guardian & $174(12.4)$ \\
\hline \multicolumn{2}{|l|}{ Birth position } \\
\hline Only child & $38(2.7)$ \\
\hline First child & $326(23.2)$ \\
\hline Last child & $313(22.3)$ \\
\hline Others & $729(51.8)$ \\
\hline \multicolumn{2}{|l|}{ Number of siblings } \\
\hline 0 & $38(2.7)$ \\
\hline $1-2$ & $245(17.4)$ \\
\hline $3-4$ & $570(40.5)$ \\
\hline$>4$ & $553(39.3)$ \\
\hline \multicolumn{2}{|c|}{ Utilization of dental services } \\
\hline 1 year ago & $60(4.3)$ \\
\hline 2 years ago & $41(3.0)$ \\
\hline 3 years ago & $18(1.3)$ \\
\hline$\geq 4$ years ago & $13(0.9)$ \\
\hline No visit & $1274(90.5)$ \\
\hline
\end{tabular}

Table 2 illustrates the socio-demographic profile of the 132 (9.4\%) pupils who had ever visited a dental clinic for oral-health services. More pupils of high socio-economic status than those with middle and low socio-economic status used the services $(p<0.001)$. Also, those living with both parents compared with those living with one parent or guardian/relatives $(p=0.003)$, and those who lived within 1-1.9 km from an oral-healthcare center compared with those who lived $2.0 \mathrm{~km}$ or more from an oral-health care center $(p<0.001)$ used oral-health care services. There was no significant difference between the type of family $(p=0.41)$, birth rank $(p=0.53)$ or number of siblings $(p=0.10)$ of pupils who had previously used the services. 
Table 2 - Distribution of study participants who had ever used oral health care services in the past $(n=132)$.

\begin{tabular}{|c|c|c|}
\hline Variable & $\begin{array}{l}\text { Frequency } \\
\mathrm{n}(\%)\end{array}$ & $\mathrm{p}$ \\
\hline Socioeconomic status & & $<0.001$ \\
\hline High & $85(64.4)$ & \\
\hline Middle & $31(23.5)$ & \\
\hline Low & $16(12.1)$ & \\
\hline Type of family & & 0.41 \\
\hline Monogamy & 124(93.9) & \\
\hline Polygamy & $8(6.1)$ & \\
\hline Familystructure & & 0.003 \\
\hline Both parents & $125(94.7)$ & \\
\hline One parent & $1(0.8)$ & \\
\hline Guardian & $6(4.5)$ & \\
\hline Birth rank & & 0.53 \\
\hline Only child & $5(3.8)$ & \\
\hline First child & $26(19.7)$ & \\
\hline Last child & $33(25.0)$ & \\
\hline Others & $68(51.5)$ & \\
\hline Number of siblings & & 0.10 \\
\hline 0 & $5(3.8)$ & \\
\hline $1-2$ & $28(21.2)$ & \\
\hline $3-4$ & $60(45.5)$ & \\
\hline$>4$ & $39(29.5)$ & \\
\hline $\begin{array}{l}\text { Distance of facility to participants' } \\
\text { residence }(\mathrm{km})\end{array}$ & & $<0.001$ \\
\hline$<1.0$ & $47(35.6)$ & \\
\hline $1.0-1.9$ & $48(36.4)$ & \\
\hline $2.0-3.9$ & $30(22.7)$ & \\
\hline$\geq 4.0$ & $7(5.3)$ & \\
\hline
\end{tabular}

Table 3 illustrates the socio-demographic profile of the $126(9.0 \%)$ pupils who visited an oral-health center after the school visit. Just as observed before the issuance of referrals, significantly more pupils from the high socioeconomic strata than those from the middle and low socio-economic strata utilized the oral-health care centers $(p<0.001)$. Family living structure was also a significant factor affecting oral health service utilization: all the study participants who utilized oral-healthcare services were living with both parents, whereas none of those living with one parent or guardian visited a center $(p<0.001)$. Again there was no statistical difference in the number of study participants from monogamous and polygamous families who utilized the oral-health care centers $(p=0.21)$ and birth rank did not significantly affect use of the services.

In contrast to the findings before the school visit, the number of siblings was related to frequency of oral-health care visits: children who had three or more siblings visited the centers more often than those who had two siblings or fewer $(p=0.002)$. Also, the distance of participants' residences from the oral-health care centers was not a factor in oral-health care utilization, whereas it was a factor before the use of referrals.
Table 3 - Distribution of study participants who utilized the oralhealth care services after referral $(n=126)$.

\begin{tabular}{|c|c|c|}
\hline Variable & $\begin{array}{l}\text { Frequency } \\
\mathrm{n}(\%)\end{array}$ & $p$ value \\
\hline Socioeconomic status & & $<0.001$ \\
\hline High & $85(67.5)$ & \\
\hline Middle & $33(26.2)$ & \\
\hline Low & $8(6.3)$ & \\
\hline Type of family & & 0.21 \\
\hline Monogamy & 123(97.6) & \\
\hline Polygamy & $3(2.4)$ & \\
\hline Familystructure & & $<0.001$ \\
\hline Both parents & $126(100.0)$ & \\
\hline One parent & $0(0.0)$ & \\
\hline Guardian & $0(0.0)$ & \\
\hline Birth rank & & 0.80 \\
\hline Only child & $4(3.2)$ & \\
\hline First child & $31(24.6)$ & \\
\hline Last child & $31(24.6)$ & \\
\hline Others & $60(47.6)$ & \\
\hline Number of siblings & & 0.002 \\
\hline 0 & $4(3.2)$ & \\
\hline $1-2$ & $36(28.6)$ & \\
\hline $3-4$ & $52(41.3)$ & \\
\hline$>4$ & $34(27.0)$ & \\
\hline $\begin{array}{l}\text { Distance of facility to participants' } \\
\text { residence }(\mathrm{km})\end{array}$ & & 0.66 \\
\hline$<1.0$ & $34(27.0)$ & \\
\hline $1.0-1.9$ & $34(27.0)$ & \\
\hline $2.0-3.9$ & $44(34.9)$ & \\
\hline$\geq 4.0$ & $14(11.1)$ & \\
\hline
\end{tabular}

Table 4 illustrates the distribution of the study participants who had either previously utilized and/or newly utilized dental services. Most of the pupils $(77.8 \%)$ who utilized the dental services after issuance of referral letters were those who had never utilized dental services prior to the issuance of referrals $(\mathrm{p}<0.001)$

Table 4 - Distribution of study participants who had visited dental centres before and/or after referral.

\begin{tabular}{lcccc}
\hline & \multicolumn{4}{l}{ Visited after referral } \\
$\begin{array}{l}\text { Visited before } \\
\text { referral }\end{array}$ & No & Yes & Total & $p$ \\
& $n(\%)$ & $n(\%)$ & $n(\%)$ & \\
\hline No & $1.176(91.9)$ & $98(77.8)$ & $1,274(90.6)$ & $<0.001$ \\
Yes & $104(8.1)$ & $28(22.2)$ & $132(9.4)$ & \\
Total & $1,280(100.0)$ & $126(100.0)$ & $1,406(100.0)$ & \\
\hline
\end{tabular}

Figure 1 shows the profile of the pupils who received preventive or curative treatment before and after the issuance of 
referrals. Before the issuance of referrals, 54 (40.9\%) of the 132 pupils received preventive treatment, while $78(59.1 \%)$ received curative treatment $(\mathrm{p}=0.003)$. In contrast, after referral, 84 $(66.7 \%)$ of the 126 pupils received preventive treatment, whereas $42(33.3 \%)$ received curative treatment $(p<0.001)$

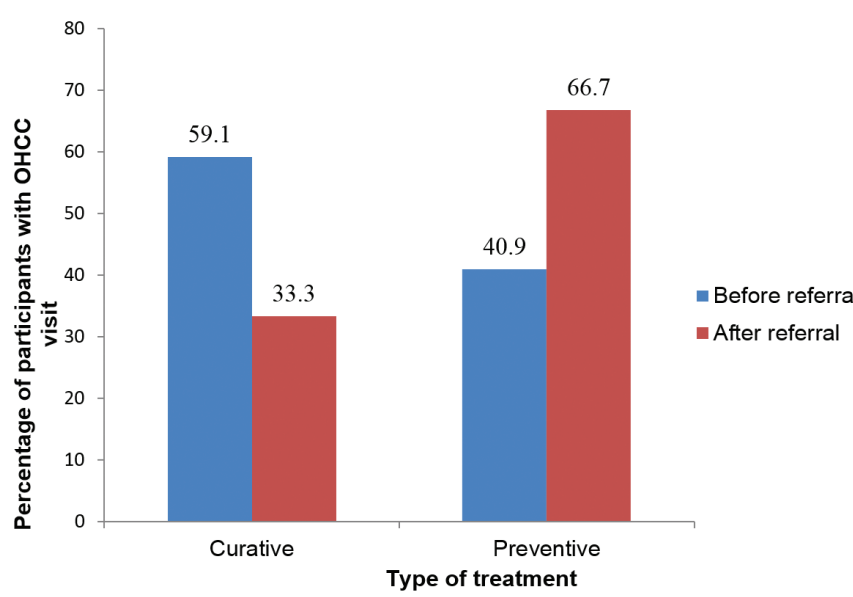

OHCC: Oral-health-care centres

Fig.1. Percentage of preventive and curative treatment received before and after referral. analysis for the best predictor of participants' utilization of oral-health care centers before the issuance of referrals. Socioeconomic status, type of family and family structure were significant predictors of dental service use. Children from middle (AOR: 0.40; CI: 0.26-0.62; p<0.001) and low socioeconomic strata (AOR: 0.19; CI: 0.11-0.34; p $<0.001$ ), those living with relatives/guardians (AOR: 0.33, CI: 0.13-0.78; $\mathrm{p}=0.01$ ), and those who lived 2.0-3.9km (AOR: 0.41, CI: 0.25-0.68; $<<0.001$ ) and more than $4 \mathrm{~km}$ (AOR: 0.24 , CI: $0.10-0.55 ; \mathrm{p}=0.001$ ) from a health care center were less likely to have utilized oral-health services. Children from polygamous homes were 2.6 times more likely than those from monogamous families to have utilized oral-health services in the past (CI: 1.12-5.98; $\mathrm{p}=0.03)$. The birth position and the number of siblings participanting in the study did not significantly affect oral health service utilization.

Table 6 shows the logistic regression analysis for the best predictor of study participants' utilization of oral-health care centers in the 12 months after the issuance of referrals. After the issuance of referrals, children from middle (AOR: 0.46; CI: $0.29-0.73 ; p=0.001)$ and low socioeconomic strata (AOR: 0.21 ; CI: $0.11-0.39 ; \mathrm{p}<0.001)$ and those living with relatives/ guardians (AOR: 0.08, CI: 0.01-0.56; p=0.01) still were less likely to have utilized oral-health services. Families with 3-4 children were 2.21 times more likely to have utilized oral-health services (CI: $1.23-3.96 ; p=0.01$ ) than the families with either fewer or more children. The significant effect of type of family and distance of residential location to closest dental clinic was lost after the issuance of referrals.
Table 5 - Logistic regression analysis of effect of factors on utilization of oral health-care services before education and referral intervention.

\begin{tabular}{|c|c|c|c|}
\hline Variable & $\begin{array}{l}\text { Multivariate } \\
\text { adjusted OR }\end{array}$ & $95 \%$ C.I & $p$ value \\
\hline \multicolumn{4}{|l|}{ Socioeconomic status } \\
\hline High & 1.00 & - & - \\
\hline Middle & 0.40 & $0.26-0.62$ & $<0.001$ \\
\hline Low & 0.19 & $0.11-0.34$ & $<0.001$ \\
\hline \multicolumn{4}{|l|}{ Type of family } \\
\hline Monogamy & 1.00 & - & - \\
\hline Polygamy & 2.6 & $1.12-5.98$ & 0.03 \\
\hline \multicolumn{4}{|l|}{ Family structure } \\
\hline With both parents & 1.00 & - & - \\
\hline With one of the parents & 0.17 & $0.022-1.29$ & 0.09 \\
\hline With relative/guardian & 0.33 & $0.13-0.78$ & 0.01 \\
\hline \multicolumn{4}{|l|}{ Birth Position } \\
\hline First child & 1.00 & - & - \\
\hline Last child & 1.65 & $0.93-2.93$ & 0.08 \\
\hline Only child & 2.62 & $0.84-8.22$ & 0.10 \\
\hline Others & 1.61 & $0.96-2.70$ & 0.07 \\
\hline \multicolumn{4}{|l|}{ Number of siblings } \\
\hline$<3$ & 1.00 & - & - \\
\hline 3-4 siblings & 1.75 & $0.99-3.09$ & 0.54 \\
\hline$>4$ siblings & 0.47 & $0.94-2.30$ & 0.09 \\
\hline \multicolumn{4}{|l|}{$\begin{array}{l}\text { Distance of facility to par- } \\
\text { ticipants residence }(\mathrm{km})\end{array}$} \\
\hline$<1$ & 1.00 & - & - \\
\hline $1.0-1.9$ & 1.03 & $0.66-1.63$ & 0.87 \\
\hline $2.0-3.9$ & 0.41 & $0.25-0.68$ & $<0.001$ \\
\hline$\geq 4.0$ & 0.24 & $0.10-0.55$ & 0.001 \\
\hline
\end{tabular}

$\mathrm{OR}=$ Odd ratio; $\mathrm{Cl}=$ Confidence Interval; Reference category $=1$

\section{Discussion}

The goal of our study was to explore how delivering referrals affected the utilization of oral health services by pupils attending schools in Enugu metropolis, Enugu State, Nigeria. The study showed that socio-economic factors and family structure were significant factors that affected access of pupils to oral-health services. Before the study intervention, pupils with low and middle socioeconomic status and those who lived with relatives/ guardians were less likely to have ever used a dental service than the pupils from high socioeconomic status or those living with parents. After referral for oral-health care, pupils from low and middle socioeconomic status and those living with relatives/ guardians were still less likely to use dental service. Following referral, more pupils who never utilized a dental service visited an oral health facility.

The use of referral letters to promote access to both prevention and curative treatment had four significant effects in this study. First, the number of pupils who visited the dental clinic within 12 months of issuing them a referral letter increased from $4.3 \%$ to $9.0 \%$. Second, the number of children who attended the dental clinic for preventive treatment as opposed to curative treatment, increased significantly. Third, a lot more pupils who had never visited the dental clinic were motivated to do so following receipt of a referral letter albeit most of these pupils were from the high socioeconomic class. Fourth, the distance between residential homes and dental service centers were no longer a barrier to dental service utilization. 
Table 6 - Logistic regression analysis of effect of factors on utilization of oral-health care services after school-based education and referral.

\begin{tabular}{|c|c|c|c|}
\hline Variable & $\begin{array}{l}\text { Multivariate } \\
\text { adjusted OR }\end{array}$ & $95 \%$ C.I & $\mathrm{p}$ value \\
\hline \multicolumn{4}{|l|}{ Socioeconomic status } \\
\hline High & 1.00 & - & - \\
\hline Middle & 0.46 & $0.29-0.73$ & 0.001 \\
\hline Low & 0.21 & $0.11-0.39$ & $<0.001$ \\
\hline \multicolumn{4}{|l|}{ Type of family } \\
\hline Monogamy & 1.00 & - & - \\
\hline Polygamy & 0.76 & $0.17-3.54$ & 0.73 \\
\hline \multicolumn{4}{|l|}{ Family structure } \\
\hline With both parents & 1.00 & - & - \\
\hline With one of the parents & 0.00 & 0.00 & 1.00 \\
\hline $\begin{array}{l}\text { With relative/guardian/ } \\
\text { step parent }\end{array}$ & 0.08 & $0.01-0.56$ & 0.01 \\
\hline \multicolumn{4}{|l|}{ Birth Position } \\
\hline First child & 1.00 & - & - \\
\hline Last child & 1.35 & $0.73-2.50$ & 0.34 \\
\hline Only child & 1.70 & $0.46-6.33$ & 0.43 \\
\hline Others & 1.32 & $0.77-2.25$ & 0.32 \\
\hline \multicolumn{4}{|l|}{ Number of siblings } \\
\hline$<3$ & 1.00 & - & - \\
\hline $3-4$ & 2.21 & $1.23-3.96$ & 0.01 \\
\hline$>4$ & 1.01 & $0.62-1.63$ & 0.99 \\
\hline \multicolumn{4}{|l|}{$\begin{array}{l}\text { Distance of facility to } \\
\text { participants residence }(\mathrm{km})\end{array}$} \\
\hline$<1.0$ & 1.00 & - & - \\
\hline $1.0-1.9$ & 0.73 & $0.47-1.15$ & 0.18 \\
\hline $2.0-3.9$ & 0.81 & $0.41-1.59$ & 0.54 \\
\hline$\geq 4.0$ & 1.98 & $0.60-6.51$ & 0.24 \\
\hline
\end{tabular}

$\mathrm{OR}=$ Odds ratio; $\mathrm{Cl}=$ Confidence Interval; Reference category $=1.00$

The increase in the number of pupils who visited the dental clinic for preventive oral-health treatment within 12 months of issuing them a referral letter may have resulted in part from the design of the study: all children were referred for oral-health care services whether they had dental symptoms or not. In the past, although school-based education programs had often conducted screening exercises, only children with treatment needs were referred to oral-health care services. This approach reinforced the emphasis on the children's curative dental treatment, not the prevention treatment. Referring children for both preventive and curative treatment encourages dentists to consider preventive oral-health care as important as curative care.

Sending children home with referrals for oral-health care may also have helped the parents to overcome their inertia to visiting dental clinics. A pointer to this is the significant high number of pupils who had never attended a dental clinic in the past who then visited a dental clinic following the issuance of a referral letter. The letter seemed also to serve as a motivator to overcome the limitations distance may otherwise place on a child's access to dental care. This study therefore reinforces the importance of referrals for improved dental service utilization by children, as highlighted by a prior study by Folayan et al.15. However, unlike the postulation of those authors, this study showed that referrals might increase access to preventive dental treatment and not just curative treatment.

A child's socioeconomic status is a risk factor for inequity in dental service access and utilization ${ }^{3,11}$. Socioeconomic status is a reflection of family's disposable income; those from the poor socio-economic status have little disposable income to pay for oral-health care, especially for preventive care ${ }^{11,20}$. The indirect costs associated with visiting the dentist (transport, off work time) may also be a barrier to use of oral-health services. This study reinforces the impact that a child's socioeconomic status has to its access to oral-health services. Strategic interventions are therefore required to help improve utilization of oral-health care services by children from the middle and low socio-economic strata. We believe that similar strategic thinking would also be required to promote access of children living with relatives/guardians to oralhealth services, even though Newacheck ${ }^{21}$ reported that family structure had no impact on oral-health service utilization after controlling the socioeconomic status.

Despite the success recorded by the use of referral letters to increase the number of pupils who utilized dental care services, oral-health service utilization by the study population was still very low. This finding is similar to findings in other developing countries $^{22,23}$, except Kenya, where higher figures have been reported ${ }^{24}$. Prior reports from Ile-Ife ${ }^{15,25}$, Ibadan $^{26}$ and Enugu ${ }^{27}$ in Nigeria - all located in Southern Nigeria - had reported higher proportions of children utilizing dental care services. Children's utilization of oral-health care services is, however, lower in North Central Nigeria ${ }^{28}$ and among children with special needs ${ }^{11}$. Further studies are required to help identify factors that would increase oral-health service utilization by pupils in the study population to both preventive and curative dental care. A mixed-method study design may be most helpful in this respect. Our study had limitations. First, the number of pupils who had previously visited oral-health clinics may have been underreported as some pupils may have utilized dental clinics outside the state where this study was conducted. Also, data of students who did not return to the schools where the study was conducted in the following academic year might not be collected. Second, the opportunity for some parents to visit the dental clinic may have been undermined if study participants did not give their parents the referral letter, which is a possibility with children. These limitations are, however, beyond the capacity of the study to address. The study therefore reflects the reality of what would happen in real life settings. Thus, the limitations identified for this study did not detract from the validity of our findings. In conclusion, this study in a Nigerian metropolis demonstrated that school-based education and referral programs overall increased pupils' use of oral-healthcare services for both preventive and curative care. However, the intervention did not improve dental service utilization by children of middle and low socioeconomic status and children who lived with relatives/ guardians. Future efforts should address factors that can reduce the inequity in access of these children to oral-health care services. 


\section{Abbreviations}

LGA: Local Government Area; SPSS: Statistical Package of Social Science; GPS: Global Positioning System; DMS: Degrees, minutes, seconds; GIS: Geographic Information System

\section{References}

1. Luzzi L, Spencer AJ. Factors influencing the use of public dental services. An application of theory of planned behavior. BMC Health Serv Res. 2008 Apr 30;8:93. doi:10.1186/1472-6963-8-93.

2. Lopez R, Baelum V. Factors associated with dental attendance among adolescents in Santiago, Chile. BMC Oral-health. 2007Apr 10;7:4. doi: 10.1186/1472-6831-7-4.

3. Kim J, Choi Y Park S, Kim JL, Lee TH, Cho KH et al. Disparities in the experience and treatment of dental caries among children aged 9-18 years: the cross-sectional study of Korean National Health and Nutrition Examination Survey (2012-2013). Int J Equity Health. 2016 Jun 7;15:88. doi:10.1186/s12939-016-0377-x.

4. Amin S M, Perez Arnado, Nyanchhyon P. Barrier to utilization of dental services for children among low income families in Alberta. J Can Dent Assoc. 2014;80:e51.

5. Heck EK, Parker DJ: Family structure, socioeconomic status and access to health care for children. Health Serv Res. 2002 Feb;37(1):171-84.

6. Adegbembo AO. Household utilization of dental services in Ibadan, Nigeria. Community Dent Oral Epidemiol. 1994 Oct;22(5Pt 1):338-9.

7. Tapias-Ledesma MA, Garrido PC, Y Pena ME, Hernanez-Barrera V, de Miquel AG, Jimenez-Garcia R. Use of dental care and prevalence of caries among immigrant and Spanish born children. J Dent Child. 2011Jan-Apr;78(1):36-42.

8. Onyejaka NK, Folayan MO, Folaranmi N. Barriers and facilitators of dental service utilization by children aged 8 to 11 years in Enugu State, Nigeria. BMC Health Serv Res. 2016 Mar 15;16:93. doi: 10.1186/s12913016-1341-6.

9. Crall JJ, Illum J, Martinez A, Pourat N. An innovative project breaks down barriers to oral health care for vulnerable young children in Los Angeles County. Policy Brief UCLA Cent Health Policy Res. 2016 Jun;(PB2016-5):1-8.

10. Adekoya-Sofowora CA. The effect of poverty on access to oral health care in Nigeria. Nig Dent J. 2008,16(1):40-2.

11. Slade GD. Epidemiology of dental pain and dental caries among children and adolescents. Community Dent Health. 2001 Dec;18(4):219-27.

12. Varenne B, Petersen P, Fournet F, Msellati P, Gary J, Quattara S et al. Illness related behavior and utilization of oral-health services among adult dwellers in Burkina Faso, evidence from household survey. BMC Health Serv Res. 2006 Dec;6:164. doi:10.1186/1472-6963-6-164.
13. Oredugba FA. Use of oral-health care services and oral findings in children with special need in Lagos, Nigeria. Spec Care Dentist. 2006 Mar-Apr;26(2):59-65.

14. Akaji EA, Oredugba FA, Jeboda SO. Utilization of dental services among secondary school students in Lagos, Nigeria. Nig Dent J. 2007;15(2):8791.

15. Folayan MO, Oziegbe E, Oyedele T, Ola D. Factors limiting dental service utilization by pupils in a suburban town in Nigeria. Niger J Health Sci. 2013,2:18-23

16. Folayan MO, Khami MR, Onyejaka N, Popoola BO, Adeyemi YI. Preventive oral-health practices of school pupils in southern Nigeria. BMC Oral-health. 2014 Jul 7;14:83. doi:1186/1472-6831-14-83.

17. National Population Commission (NPC) [Nigeria] and ICF International 2014. Nigeria Demographic and Health Survey 2013. Abuja, Nigeria, and Rockville, Maryland, USA: NPC and ICF International.

18. Araoye MO. Research methodology with statistics for health and socia sciences. Ilorin: Nathadex Publisher; 2003. p.115-9.

19. Enugu State Ministry of Education. Annual school census report 20092010, Enugu. Esspin; 2010. p.1-8.

20. Blishen BR. Indices of social classification. In: Merton RK. Social stratification- a comparative analysis of structure and process. 2nd ed. Harcourt Brace; 1957. p.78-185.

21. Newacheck PW: Characteristics of children with high and low usage of physician services. Med Care. 1992 Jan;30(1):30-42.

22. Baldani MH, Mendes YB, Lawder JA, de Lara AP, Rodrgues MM, Antunes $\mathrm{JL}$. Inequalities in dental services utilization among Brazilian low income children: the role of individual determinants. J Public Health Dent. 2011 Winter;71(1):46-53.

23. Mantonanaki M, Koletsi-Kounari H, Mamai-Homata E, Papaioannou W. Prevalence of dental caries in 5 year old Greek children and the use of dental services: evaluation of socioeconomic, behavioural factors and living conditions. Int Dent J. 2013 Apr;63(2):72-9.

24. Owino RO, Masiga MA, Macigo FG, Nganga PM. Oral-health knowledge, hygiene practices and treatment seeking behaviour among 12 year old children from Kitale municipality in Kenya. East Afr Med J. 2011 Oct;:88(10):332-6.

25. Ola D, Gamboa AB, Folayan MO, Marcenes W. Family structure, socioeconomic status and oral-health service utilization in Nigerian Senior Secondary school students. J Public Health Dent. 2013 Spring;73(2):158-65

26. Denloye OO, Bankole OO, Onyeaso CO: Dental health service utilization by children seen at the University College Hospital-an update. Trop Dent J. 2004:27:29-32.

27. Okoye LO, Chukwuneke FN, Akaji EA, Folaranmi N. Caries experience among school children in Enugu, Nigeria. J Coll Med. 2010; 15(2):17-23.

28. Adeleke OA, Danfillo IS. Utilization of oral-health services by mothers of preschool children in Jos North Local Government Area, Plateau State, Nigeria. Malawi Med J. 2005;16(2):33-6. 